\title{
CARACTERIZAÇÃO DE ACIDENTE COM MATERIAL PERFUROCORTANTE E A PERCEPÇÃO DA EQUIPE DE ENFERMAGEM
}

\author{
Alessandra Saldanha Ribeiro ${ }^{1}$, Ruth Irmgard Bärtschi Gabatz², Eliane Tatsch Neves³ ${ }^{3}$, Stela Maris de Mello Padoin ${ }^{4}$
}

\begin{abstract}
RESUMO: Trata-se de estudo descritivo cujos objetivos foram caracterizar o acidente com material perfurocortante e conhecer a percepção da equipe de Enfermagem diante do acidente. Os dados foram coletados por meio de entrevista com 22 profissionais de enfermagem de um hospital universitário do Sul do Brasil, no período de março a maio de 2008. A análise ocorreu conforme conteúdo e frequência, aplicando-se a análise temática. Os resultados revelaram que a situação do acidente envolve: descuido/distração no momento do acidente; a agulha como principal material; as mãos são mais atingidas; a não utilização de precaução padrão e a falta de notificação do acidente. É necessário que as instituições de ensino e de assistência programem medidas para melhorar a segurança no trabalho, pela estrutura organizacional e educação permanente para práticas de biossegurança.
\end{abstract}

PALAVRAS-CHAVE: Enfermagem; Precauções universais; Acidentes de trabalho; Síndrome da imunodeficiência adquirida.

\section{CHARACTERIZATION OF ACCIDENT WITH NEEDLESTICK MATERIALS AND THE NURSING PROFESSIONALS’ PERCEPTION}

\begin{abstract}
It is a descriptive study that aimed to characterize the accident with needlestick materials and knowing the perception of nursing professionals in face of these accidents. Data were collected through interviews with 22 nursing workers at a teaching hospital in the southern Brazil from March to May 2008. Data were analyzed by thematic analyses according to the content and its frequency. The results pointed out that the accident situation involves: professionals' negligence/distraction; the needle as the main material involved; the hands as more affected; non- adoption of standard procedures, and non-reported occupational accidents. In conclusion, it is necessary that teaching and assistance institutions improve the work security conditions by organizational structure and education to biosafety practices.
\end{abstract}

KEYWORDS: Nursing; Universal precautions; Accidents; Occupational; Acquired immunodeficiency syndrome.

\section{CARACTERIZACIÓN DEL ACCIDENTE CON MATERIAL CORTO-PUNZANTE E LA PERCEPCIÓN DEL EQUIPO DE ENFERMERÍA}

RESUMEN: Se trata de un estudio descriptivo cuyos objetivos fueron caracterizar el accidente con material cortopunzante y conocer la percepción del equipo de Enfermería delante del accidente. Los datos fueron recolectados por medio de entrevista con 22 profesionales de enfermería de un hospital universitario del sur de Brasil, en el periodo de marzo a mayo de 2008. El análisis ocurrió conforme contenido y frecuencia, aplicándose el análisis temático. Los resultados revelaron que la situación del accidente involucra: descuido/distracción en el momento del accidente, la aguja como principal material; las manos son más afectadas; la no utilización de precaución patrón y la falta de notificación del accidente. Es necesario que las instituciones de enseñanza y de asistencia programen medidas para mejorar la seguridad en el trabajo, por la estructura organizacional y educación permanente para prácticas de bioseguridad.

PALABRAS CLAVE: Enfermería; Precauciones universales; Accidentes de trabajo; Síndrome de la inmunodeficiencia adquirida.

\footnotetext{
${ }^{1}$ Enfermeira. Residente do Programa de Residência Multiprofissional Integrada em Sistema Público de Saúde da Universidade Federal de Santa Maria-UFSM-RS.

${ }^{2}$ Enfermeira. Mestre em Enfermagem pela UFSM. Professora do Curso de Graduação em Enfermagem da Sociedade Educacional Três de Maio-SETREM.

${ }^{3}$ Enfermeira. Docente no Curso de Graduação e de Pós-Graduação em Enfermagem na UFSM-RS.

${ }^{4}$ Enfermeira. Docente no Curso de Graduação e de Pós-Graduação em Enfermagem na UFSM-RS.
}

Autor correspondente:

Ruth Irmgard Bärtschi Gabatz

Sociedade Educacional Três de Maio

Av. Santa Cruz, 741 - 98900-000 - Santa Rosa-RS, Brasil

Recebido: 14/08/09

E-mail: rb-gabatz@uol.com.br

Aprovado: 20/10/09

Cogitare Enferm 2009 Out/Dez; 14(4):660-6 


\section{INTRODUÇÃO}

Instituições hospitalares brasileiras, a partir do início da década de 1970, especialmente pesquisadores da Universidade de São Paulo, começaram a pesquisar a saúde ocupacional de trabalhadores hospitalares. A partir de 1968, com a criação do Instituto Nacional da Previdência Social, os acidentes de trabalho passaram a ser considerados como indicadores indiretos das condições de trabalho. Com isso, os acidentes de trabalho surgiram de forma quantitativa e, de certo modo, passaram a constituir um problema de saúde pública, afetando inclusive a economia do país ${ }^{(1-2)}$.

Entretanto, a preocupação com riscos biológicos aponta maior preocupação a partir do surgimento do Human Infection Virus-HIV nos anos 1980 e da epidemia da Adquired Immunity Deficiency SyndromeAIDS. Até então, os trabalhadores da área da saúde não eram considerados como categoria de alto risco para acidentes de trabalho, mesmo que o risco ocupacional com agentes infecciosos tenha sido conhecido desde o início dos anos 40 do século $\mathrm{XX}^{(1-4)}$.

Segundo os Centers for Disease Control and Prevention-CDC, o risco de contaminação ocupacional pelo HIV é de $0,3 \%$, pelo vírus da hepatite B (HBV) é de $6 \%$ a $30 \%$ e o risco de contaminação para hepatite $\mathrm{C}(\mathrm{HCV})$ é de $0,5 \%$ a $2 \%$. À medida que a prevalência da AIDS e hepatite aumenta, considera-se que a chance de um profissional da saúde entrar em contato com o HIV por meio de exposição ocupacional também se eleva ${ }^{(5)}$.

Nesse sentido, a crescente preocupação com a transmissão de doença infectocontagiosa por meio de acidentes com material perfurocortante e fluidos corpóreos fez com que sistemas de vigilância epidemiológica fossem criados na maioria dos hospitais, principalmente após a expedição pelo Ministério da Saúde, em junho de 1983, da Portaria $n^{\circ} 930^{(5)}$. Foram então estabelecidas normas para as questões de segurança no ambiente de trabalho, bem como implantada e mantida uma Comissão de Controle de Infecção Hospitalar-CCIH em todos os hospitais do Brasil. Foram concebidas Normas RegulamentadorasNRs, que obrigam todas as instituições privadas ou públicas que empregam trabalhadores regidos pela consolidação das leis do trabalho-SESMT a fornecer equipamentos de proteção individual-EPI e realizar um programa de controle médico de saúde ocupacional.

Apesar de o risco de contaminação com o vírus da hepatite ser maior, a grande preocupação dos profissionais que se expõem a acidentes com sangue e secreções do paciente é de contrair a infecção pelo HIV, ainda hoje estigmatizada e discriminada, inclusive pelos profissionais da área da saúde ${ }^{(6)}$.

Assim, os objetivos deste estudo foram caracterizar o acidente com material perfurocortante e conhecer a percepção da equipe de Enfermagem diante do acidente.

\section{MATERIAIS E MÉTODOS}

Trata-se de um estudo descritivo com abordagem quanti-qualitativa com profissionais da equipe de enfermagem e estudantes de enfermagem em um hospital universitário do Sul do Brasil. O cenário do estudo é um complexo hospitalar de referência regional para usuários do Sistema Único de SaúdeSUS que presta atendimento em diferentes especialidades na área da saúde e tem por finalidade a assistência, o ensino, a pesquisa e a extensão.

Os sujeitos do estudo foram 22 profissionais e estudantes-bolsistas de enfermagem, dentre eles: quatro enfermeiros, dois acadêmicos, 13 técnicos de enfermagem e três auxiliares de enfermagem. Desses participantes, 14 trabalhavam na Unidade de Clínica Médica-UCM e oito na Unidade de Terapia Intensiva Adulto-UTI.

Os trabalhadores e estudantes foram entrevistados nos seus respectivos locais de trabalho após a aprovação do Comitê de Ética e Pesquisa da instituição de ensino, preservando os aspectos éticos de pesquisas envolvendo seres humanos (aprovação CAAE $n^{0}$. 0022.0.243.000-08). A seleção foi feita por meio de sorteio entre todos os funcionários que se encontravam na unidade nos turnos em que os dados foram coletados, o que se deu com o auxílio da enfermeira de plantão.

Os dados foram coletados no período de março a maio de 2008, por meio de entrevista semiestruturada, com questões abertas e fechadas. Na primeira parte constavam questões relativas à caracterização dos profissionais respondentes; na segunda a situação em que o acidente aconteceu; na terceira os encaminhamentos dos acidentes com perfurocortantes e na quarta percepções e sentimentos desencadeados pelo acidente.

A análise dos dados foi constituída de duas etapas. A primeira constituiu-se da análise quantitativa das três primeiras partes do instrumento, que foram classificadas conforme o conteúdo e a frequência dos 
dados, agrupando-os nas categorias pré-estabelecidas: caracterização dos respondentes e situação da ocorrência do acidente.

A segunda etapa constitui-se de análise qualitativa, que correspondeu às questões respondidas na quarta parte do instrumento. Foi aplicada a análise temática proposta por Minayo ${ }^{(7)}$, que contemplou a ordenação dos dados, com a releitura das entrevistas e utilização de códigos numéricos para a identificação dos sujeitos (E1, E2, E3...). Posteriormente, foi realizada a leitura para identificar ideias centrais do texto e aspectos relevantes para a classificação dos conteúdos. Finalmente, procurou-se uma articulação entre o material estruturado nas entrevistas com o referencial teórico do estudo.

\section{APRESENTAÇÃO E DISCUSSÃO DOS RESULTADOS}

Após a análise dos resultados, os achados foram assim organizados: a) caracterização dos respondentes; b) os acidentes perfurocortantes e a sua situação de ocorrência; c) os sentimentos dos profissionais acerca do acidente com material perfurocortante.

\section{Caracterização dos respondentes}

Quando questionados sobre a ocorrência de acidentes com objetos perfurocortantes, 12 dos 22 respondentes referiram já terem sofrido esse tipo de acidente. Os profissionais entrevistados, que sofreram acidente com material perfurocortante, eram majoritariamente mulheres, sendo somente um homem. Esses resultados convergem com a constituição da equipe de enfermagem em que predominam mulheres, fazendo com que sejam as principais vítimas deste tipo de acidente de trabalho ${ }^{(8-11)}$.

Os resultados indicaram que os auxiliares de enfermagem sofreram mais acidentes, seguidos dos técnicos de enfermagem. Vale destacar que o número de técnicos, neste estudo, foi menor que o número de auxiliares. Os enfermeiros e acadêmicos de enfermagem bolsistas aparecem logo após como aqueles mais atingidos pelos acidentes, na mesma proporção que outros estudos já têm demonstrado ${ }^{(3,5,10-11)}$.

A frequência de acidentes acima distribuída entre os componentes da equipe de enfermagem justifica-se pelo fato de os técnicos e auxiliares estarem em contato direto com o paciente, na maior parte do tempo, realizando curativos, administrando medicamentos e outros procedimentos que os mantêm em constante contato com materiais perfurocortantes. Já os enfermeiros envolvem-se mais frequentemente com as atividades administrativas ${ }^{(3,5,10-11)}$.

A idade dos profissionais que sofreram acidente oscilou entre 20 e 40 anos e o tempo de atuação profissional entre 1 e 10 anos. Nesse sentido, podemse considerar como principais motivos para esse tipo de acidente entre os funcionários com maior experiência o não-cumprimento das normas de segurança ou das precauções padrão e, entre os funcionários com menor tempo de atuação, a insegurança e a pouca habilidade técnica até então adquirida.

Compreendemos neste estudo, em consonância com outros, que tal resultado pode estar relacionado a lacunas na formação desses profissionais ou à falta de capacitações permanentes ${ }^{(12-13)}$ e, ainda, isso poderá estar associado às condições de trabalho.

\section{Os acidentes perfurocortantes e a sua situação de ocorrência}

Dentre os 12 sujeitos que sofreram acidente perfurocortante, oito deles trabalhavam na unidade de clínica médica e quatro na unidade de terapia intensiva. Um desses profissionais sofreu o acidente em outra instituição que não o cenário do estudo. Esse resultado vem ao encontro de alguns estudos que demonstram que profissionais de unidades de clínica médica ou cirúrgica estão mais expostos a esse tipo de acidente, devido à sobrecarga de trabalho, ao número de procedimentos invasivos somado às condições de trabalho ${ }^{(1,11-12)}$.

Em relação ao turno de trabalho em que o acidente ocorreu, o estudo demonstrou uma igualdade na distribuição pelos três turnos, discordando de algumas pesquisas que trazem os turnos da manhã e da tarde como os maiores acometidos, principalmente pelo ritmo mais intenso de trabalho nesses turnos ${ }^{(3,9-11)}$.

Quando questionados acerca do uso de EPI ou de alguma precaução padrão durante o manuseio com objetos perfurocortantes, nove dos respondentes referiram não usar precaução padrão nenhuma. Somente três afirmaram usar luvas durante o procedimento em que ocorreu o acidente. Tal fato corrobora os achados na literatura, relacionando-os à resistência na utilização de equipamentos de proteção individual pelos profissionais ou, ainda, à subestimação do risco a que estão expostos ${ }^{(3-4,12-13)}$. 
A conscientização dos profissionais sobre o uso frequente dos dispositivos de segurança para precauções padrão é imprescindível, visto que, principalmente durante atendimentos de urgência/emergência, é difícil a identificação da situação de soropositividade ao HIV. Assim, faz-se necessário reforçar a compreensão sobre a possibilidade de que qualquer pessoa pode ser potencialmente infectada. Em vista disso, preconiza-se a adoção de medidas especiais para a proteção dos trabalhadores de saúde como uma condição fundamental para a sua segurança $a^{(6,8)}$.

O principal objeto causador de acidentes citado pelos profissionais foi a agulha, que aparece como uma das principais responsáveis pelo número de acidentes, devido ao seu intenso manuseio pela equipe de enfermagem no preparo e administração de medicações e na realização de exames. Esse achado converge com vários estudos, nos quais a agulha também aparece como o objeto mais associado aos acidentes $^{(3,9,11-13)}$.

A região mais afetada pelos acidentes foram as mãos, principalmente os dedos. Isso pode ser relacionado com a não utilização das precauções padrão, como luvas,

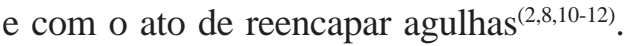

Quanto às circunstâncias dos acidentes, evidenciou-se que cinco ocorreram mediante a presença de agulha ou material cortante em local impróprio, como leito, mesa de cabeceira ou bandeja de medicações. Alguns estudos destacam o descarte inadequado de material perfurocortante como uma das principais causas para o acidente, o que pode acarretar danos não só à equipe de enfermagem, mas também aos demais profissionais no ambiente hospitalar ${ }^{(4,10)}$.

A realização de glicemia capilar foi apontada como o procedimento que causou três situações de acidente no momento do reencape de agulhas. Após realização e retirada de punção venosa também ocorreram acidentes, motivados por descuido ou distração. Na aspiração de medicação, ocorreram duas situações de acidente relacionadas à pressa e à emergência.

Quanto ao conhecimento e à conduta tomada após o acidente pelos profissionais, perceberam-se divergências entre as respostas. Nove profissionais referiram ter conhecimento sobre a conduta em caso de acidente com objeto perfurocortante. Porém, quando questionados quanto à conduta que tomaram após o acidente, surgiram respostas como:

[...] nenhuma devido à sorologia do paciente ser negativa para doenças infectocontagiosas [...]
Outros comunicaram somente dois dias após o acidente ter ocorrido, por medo de perderem o emprego em um serviço privado ou para evitar constrangimentos ao paciente por um erro que não foi dele. Dessa forma, somente cinco dos 12 acidentes foram notificados ao serviço responsável, por ter sido considerada a potencialidade do risco de contaminação. Evidenciouse que a falta de notificação ocorreu porque as vítimas consideraram o acidente sem importância, ou porque o material não tinha sido utilizado em pacientes, ou ainda pelo desconhecimento referente ao dever de comunicar o acidente.

Tais dados são convergentes com outros estudos que evidenciaram um elevado índice de sub-notificação dos acidentes com perfurocortantes ${ }^{(1-3,11-12,14)}$. Essas atitudes impedem que as instituições tenham noção da verdadeira dimensão do problema, fazendo com que ações de prevenção e controle dos acidentes sejam de difícil planejamento e desenvolvimento.

Do total de acidentes perfurocortantes sofridos pelos sujeitos deste estudo, somente um envolveu paciente com sorologia positiva para o HIV e hepatite C, existindo a necessidade de tratamento quimioprofilático para o trabalhador. Entretanto, o profissional não terminou o tratamento por considerar pequena a chance de contrair a doença e, principalmente, por considerá-lo desnecessário. Nessa situação, havia iniciado o tratamento há 48 horas após o acidente, considerando que estudos mostram a importância e eficácia do tratamento se iniciado até duas horas após o acidente ${ }^{(1,6)}$. O profissional relatou, ainda, que não apresentou efeitos colaterais ao tratamento, decidindo desistir por vontade própria. As dificuldades relatadas para o tratamento foram: o tempo de espera de encaminhamento do acidente de trabalho, a necessidade de acompanhamento periódico e de tratamento diário e prolongado.

Assim, evidenciou-se a necessidade não só de oferecer informações que propiciem as ações de atendimento ao trabalhador que sofre um acidente perfurocortante, tendo em vista os aspectos físicos, psíquicos e emocionais que acompanham esse tipo de situação, como também considerar as suas relações familiares e sociais ${ }^{(12,14)}$.

\section{Os sentimentos dos profissionais acerca do acidente com material perfurocortante}

Em relação aos sentimentos despertados nos depoentes no momento do acidente, surgiram respostas 
como medo, desespero, apreensão, preocupação, angústia, culpa e constrangimento diante do paciente. A indiferença em relação ao fato aparece nas situações em que o profissional buscou conhecer a sorologia do paciente e este não era portador do $\mathrm{HIV}^{(12)}$.

Para oito dos entrevistados, ficou evidente o medo de se infectarem com o HIV e não com os vírus da hepatite B e C, como segue:

[...] porque tu pegar uma doença dessas trabalhando é brabo, se tu ainda andasse pela rua [...] tudo bem, mas trabalhando [...] (E 1).

Desse modo, percebe-se que a contaminação para hepatite, mesmo tendo índices bem maiores, não preocupa os entrevistados, os quais deixaram transparecer, em alguns depoimentos, a discriminação e o preconceito que o HIV/AIDS ainda carrega ${ }^{(4,6,12)}$.

Tal situação poderá estar relacionada ao surgimento e à evolução da epidemia do HIV, porque durante muito tempo a AIDS esteve associada a comportamentos tidos como inadequados pela sociedade, por estar relacionada inicialmente a grupos marginalizados - como usuários de drogas injetáveis, homossexuais, prostitutas - e ser considerada uma doença altamente contagiosa, incurável e mortal. Ao ser vista como uma doença maligna, uma "peste", mobilizava sentimentos de desprezo e preconceito em relação aos infectados pela doença ${ }^{(11,15,17)}$.

No entanto, das notificações dos casos de AIDS e dos estudos de perfil das pessoas com sorologia positiva para o HIV surgem as situações relacionadas aos contextos sociais e também às vivências de pessoas infectadas ou doentes de AIDS. Essas situações são consideradas circunstâncias individuais e sociais que aproximam as pessoas da epidemia da AIDS.

Dos boletins epidemiológicos, têm-se conclusões da evolução da epidemia no Brasil, como: a feminização, que se refere ao aumento do número de notificações entre as mulheres; a pauperização, que se refere ao aumento do número de casos de AIDS em pessoas mais pobres, além da juvenilização, que se refere ao aumento de jovens infectados. Além disso, na última década, houve o aumento de casos entre pessoas com mais de 50 anos. Essas questões são implicações determinantes e interpedendentes de um contexto socioeconômico-cultural e de uma política pública.

Nesse sentido, percebe-se que ainda predomina a imagem de que essas pessoas devam ser excluídas e isoladas do convívio social por representarem perigo para a sociedade. São, assim, por muitas vezes abandonadas pela família, pelos amigos e até mesmo por profissionais, que, apesar de possuírem conhecimento sobre a doença, têm receio da infecção ${ }^{(15)}$, como aparece no seguinte relato:

Eu não me importei muito com o acidente porque sabia que o paciente não tinha nenhuma doença que podia me contaminar, mas se, por exemplo, ele fosse um paciente HIV e ía entrar em desespero, porque querendo ou não a gente sempre tem um pouco de preconceito, medo desses pacientes [...]. Vai dizer que se tu soubesse que um empregado teu fosse HIV tu ía deixar ele continuar numa boa, cuidando da tua casa, dos teus filhos [...] porque a gente nunca sabe, tem muitos que não aceitam essa situação $e$ querem infectar todo mundo [...] é complicado (E 2).

Porque eu fico pensando o que seria da minha vida caso me contaminasse com o HIV [...] como eu contaria para o meu esposo, prá minha família? [...] como que as pessoas passariam a me tratar daí em diante, acho que eu não aguentaria passar por tudo que eles passam o meu marido então nunca iria acreditar que eu me contaminei trabalhando (E 3).

Percebem-se, nos depoimentos, o medo e a preocupação que os profissionais apresentam no cuidado e na convivência com pacientes que têm sorologia positiva ao HIV. Também fica claro que temem a possibilidade de vivenciarem e suportarem o sofrimento, o abandono e a discriminação a que esses pacientes são submetidos. Eles temem o julgamento dos amigos, do/a cônjuge e da sociedade se forem infectados no acidente de trabalho, pois reconhecem o estigma das pessoas que são portadoras do HIV. Essa situação também foi achado de pesquisa desenvolvida em hospital da rede pública estadual do Ceará(12).

Ao serem questionados acerca do cotidiano de trabalho após o acidente, somente um dos entrevistados afirmou não ter alterado sua rotina. $\mathrm{O}$ achado converge com outros estudos em que os profissionais passaram a atuar com mais atenção, cautela, cuidado, não reencapando mais as agulhas, usando luvas e considerando todos os pacientes como de risco ${ }^{(12,15-16)}$.

\section{CONSIDERAÇÕES FINAIS}

Destaca-se a necessidade de os serviços de saúde voltarem sua atenção às questões referentes aos 
acidentes de trabalho, constantes no cotidiano laboral da equipe de saúde, bem como direcionar e facilitar as medidas para a notificação e encaminhamento dos acidentes. É necessário, ainda, buscar a conscientização da equipe de saúde sobre os benefícios dessa notificação, a qual auxilia a evidenciar a dimensão do problema, propiciando a implantação de medidas de prevenção. Nesse sentido, compreende-se a necessidade de parcerias entre as instituições de ensino e as de assistência, no sentido de preparar desde a formação para práticas de biossegurança, nas quais todos os materiais biológicos sejam considerados de risco.

Compreende-se que não só os profissionais, estudantes e docentes, mas também os dirigentes de instituições estejam cientes do direito e do dever de seguir os princípios de precauções padrão, considerando-as como medidas profiláticas que se aplicam não somente ao sangue, mas também a todos fluídos corpóreos, secreções, excreções, pele intacta, mucosa contendo ou não sangue visível.

Ressalta-se, também, a importância da utilização dos equipamentos de proteção individual e a realização de vacinas contra o tétano e a hepatite $B$, salientando sempre o cuidado com a manipulação e o descarte do material perfurocortante, a fim de evitar esse tipo de acidente que causa aos envolvidos transtornos não só físicos como também emocionais.

É necessário as instituições programarem medidas para melhorar as condições de trabalho e de segurança no trabalho, não só aquelas implementadas por medidas asseguradas pela estrutura organizacional, que envolvem as condições de trabalho da equipe de enfermagem, como também aquelas pautadas nas possibilidades de mudanças de comportamentos mediadas pela educação permanente para práticas de biossegurança.

Por fim, há a necessidade de um processo de educação em serviço que contemple o tema transmissão do HIV, da Hepatite B e de outras doenças infecciosas, focalizando a sensibilização da equipe de enfermagem no sentido de demover a idéia de grupos de risco. Percebe-se a importância de uma mudança na compreensão da transmissão de doenças, para que seja prestada uma assistência não só balizada nas normas e precauções padrão, como também em cuidados humanizados.

\section{REFERÊNCIAS}

1. Ribeiro EJG, Shimizu HE. Acidentes de trabalho com trabalhadores de enfermagem. Rev Bras Enferm. 2007 Set/Out;60(5):535-40.

2. Kirchhof ALC, Capellari C. Descrição das comunicações de acidentes de trabalho registradas no Instituto Nacional de Seguridade Social de Santa Maria, RS, no ano de 2000. Rev Gaúcha Enferm. 2004 Ago;25(2):194201.

3. Paulino DCR, Lopes MVO, Rolin ILTP. Biossegurança e acidentes de trabalho com pérfuro-cortantes ente profissionais de enfermagem de Hospital Universitário de Fortaleza-CE. Cogitare Enferm. 2008 Out/ Dez;13(4):507-13.

4. Marziale MHP, Rodrigues CM. A produção científica sobre os acidentes de trabalho com material pérfurocortante entre trabalhadores de enfermagem. Rev Latino-Am Enferm. 2002 Jan/Fev;10(4):571-7.

5. Ministério da Saúde (BR). Recomendações para atendimento e acompanhamento de exposição ocupacional a material biológico: HIV e hepatite B e C. Brasília, 2004.

6. Gir E, Takahashi RF, Oliveira MAC, Nichiata LYI, Ciosak SI. Biossegurança em DST/AIDS: condicionantes da adesão do trabalhador de enfermagem às precauções. Rev Esc Enferm USP. 2004 Set;38(3):245-53.

7. Minayo MCS. O desafio do conhecimento: pesquisa qualitativa em saúde. $10^{a}$ ed. São Paulo: HucitecAbrasco; 2007.

8. Marziale MHP, Nishimura KYN, Ferreira MM. Riscos de contaminação ocasionados por acidentes de trabalho com material pérfuro-cortante entre trabalhadores de enfermagem. Rev Latino-Am Enferm. 2004 Jan/ Fev;12(1):36-42.

9. Canini SRMS, Moraes SA, Gir E, Freitas ICM. Fatores associados a acidentes percutâneos na equipe de enfermagem de um hospital universitário de nível terciário. Rev Latino-Am Enferm. 2008 Set/Out;16(5):818-23

10. Sêcco IAO, Robazzi MLCC, Shimizu DS, Rúbio MMS Acidentes de trabalho típicos envolvendo trabalhadores de hospital universitário da região sul do Brasil: epidemiologia e prevenção. Rev Latino-Am Enferm. 2008 Set/Out;16(5):824-31.

11. Oliveira BAC, Kluthcovsky ACGC, Kluthcovsky FA. Estudo sobre a ocorrência de acidentes de trabalho com material biológico em profissionais de enfermagem de um hospital. Cogitare Enferm. 2008 Abr/Jun;13(2):194205. 
12. Lima FA, Pinheiro PNC, Vieira NFC. Acidentes com material pérfuro-cortante: conhecendo os sentimentos e as emoções dos profissionais de Enfermagem. Esc Anna Nery Rev Enferm. 2007 Jun;11(2):205-11.

13. Cirelli MA, Figueiredo RM, Zem-Mascarenhas SH. Adesão às precauções padrão no acesso vascular periférico. Rev Latino-Am Enferm. 2007 Mai/ Jun;15(3):512-14.

14. Sailer GC, Marziale MHP. Vivência dos trabalhadores de enfermagem frente ao uso dos antiretrovirais após exposição ocupacional a material biológico. Texto Contexto Enferm. 2007 Jan/Mar;16(1):55-62.

15. Almeida MRCB, Labronici LM. A trajetória silenciosa de pessoas portadoras do HIV contada pela história oral. Cienc Saúde Col. 2006 Jan/Mar;12(1):263-74.

16. Correa CF, Donato M. Biossegurança em uma unidade de terapia intensiva: a percepção da equipe de enfermagem. Esc Anna Nery Rev Enferm. 2007 Jul;11(2):197-204.

17. Vieira M, Padilha MICS. O HIV e o trabalhador de enfermagem frente ao acidente com material pérfurocortante. Rev Esc Enferm USP. 2008 Dez;42(4):804-10. 